\title{
Investigating the Perceptions of Sindhi Parents Towards Additive and Subtractive Bilingualism and Bilingual Education in Sindh, Pakistan
}

\author{
Pirah Hafeez MS scholar \\ Mehran University of Engineering and Technology, Jamshoro Sindh \\ Sadia Memon, English lecturer \\ Mehran Unibersity of Engineering and Technology, Jamshoro, Sindh
}

\begin{abstract}
Pakistan is linguistically and culturally diverse country where more than 70 languages are spoken. Primary education in mother tongue is a basic human right of every child and this right has been denied in private education sector of the country. The division of education among private and public sectors have further pulled the tensions and division among the masses. Language in education policies have been not been dealt with serious consideration in the entire history of Pakistan. Further proliferation of private schools in Pakistan has sidelined the role of indigenous languages in educational domain especially at primary schooling. Private schools are teaching through the subtractive bilingualism mode where one language is being preferred over other languages in teaching and learning context. This paper intends to explore perceptions of Sindhi parents towards additive and subtractive bilingualism in private schools at primary schooling and how this one language policy in schools is affecting their children. For this purpose, 16 semi-structured interviews have been conducted through maximum variation sampling. The data is collected from four districts of the Sindh; Dadu, Hyderabad and Qambar \& Shahdadkot. The results showed that parents hold different perceptions about additive/subtractive bilingualism. Out of 16 participants, 6 supported additive bilingualism and rest supported subtractive bilingualism. Results showed that parents were curious that English rather than helping create confusion and frustration for children at this very young age. Therefore, additive bilingualism must be supported that it not only facilitates children but also helps them to grasp complex concepts easily. They demanded that Mother tongue teaching must be supported in private schools
\end{abstract}

Keywords: additive bilingualism, subtractive bilingualism, mother tongue education, English language teaching, language in education policy

DOI: $10.7176 / J L L L / 84-03$

Publication date: December $31^{\text {st }} 2021$

\section{Introduction}

Bilingual education is widely recognized as a standard way to cater the educational needs and address the issues related to language planning. Pakistan is a multilingual country with 6 major 56 minor languages spoken in Pakistan. Major languages of Pakistan are Punjabi, Pashto, Sindhi, Siraiki, Balochi, Hindko, Brahvi, and others (Rahman 1997). Other languages spoken in Pakistan include Bengali, Dhatki, Gujrati, Potwari, Kalash, Khowar, Shina, Balti, Buruhi, Hindko, Farsi and the rest. According to Ethnologue, the number of individual languages listed for Pakistan is 74 (Siddique, 2019). Keeping this rich heritage in mind, a clear-cut language policy for language in education has not been proposed and language in education is handled politically (Channa, et al 2016). Urdu and English are used as languages of power in Pakistan. Urdu is used as national language and lingua franca of Pakistan and English as an official language of Pakistan. These prioritized languages have marginalized other regional languages of Pakistan. Despite of offering many language policies proposed in education commissions and conferences targeted goals have not been achieved to boost quality education in country (Patha, et al, 2016). This hegemonic behavior of English specifically in private sector schools and Urdu as medium of instruction has sidelined mother tongue education resulting weak transmission of indigenous languages to children in their early years in schools.

Schools are major cites of learning of children cognitively and socially. The increasing dominance of English and other state languages in educational institutions is denying the right of mother tongue education which not only obstructs their learning but also compels them to create positive or negative image about their self identity resulting in their alienation from their language. Therefore, schools contribute majorly for language loss and maintenance (Kangas, 2014).

\section{Significance of the Study}

Language is a most sentimental issue which needs to be handled carefully and critically. The language to be used in education system requires great attention and study before formulating language policy. Education in mother 
tongue at least at primary education is a fundamental birth right of every child in the world. (UNESCO, 1953). Pakistan is a country still struggling with literacy. In Pakistan, language in education policies has never been clearcut and transparent. English and Urdu have always been privileged languages of Pakistan and central in medium of instruction at the neglect of 70 languages of Pakistan. The neglect of first language of children would not only snatch their basic human right but it will also result in language loss (Cummin, 2006, Kangas, 2009) This study is significant because it will critically evaluate and explore the issue of language of instruction and mother tongue education right in the parental perspective and what believes they hold about bilingual educations and how seriously they are maintaining and transmitting their language to next generation. The study

\section{Research Objectives}

- To investigate the perceptions of parents towards additive and subtractive bilingualism and bilingual education at primary schooling.

- To investigate the perception of parents regarding the implications (positive/negative) of bilingual education.

\section{Literature Review}

The growth of any nation depends upon multiple factors but among those the most vital asset is the education system. Educated society can take path towards prosperity, growth, peace and healthy society. The most important thing in education is how learning and teaching takes place and through what channel. Medium of instruction is the most integral part of education system which should be decided carefully. Medium of instruction is defined as; vehicle for teaching and learning; The decision about what language will be used for instruction is based on country's language policy which shapes the perception of masses in any language (Channa, et al 2016).

A language shows vital part in the life of human being. We as humans comprehend this world and internalize the worldview through the medium of our language. Language is not only limited as a medium of communication and a tool to understand this world but it is also marker of our identity and integral part of our cultures (Desoi,2007)

Language policies can affectively impact on all stakeholders. Parents are bearers and sufferers of the outcome of language policies. Therefore, any decision regarding MOI should be taken into consideration with the opinions of the directly involved stakeholders, i.e., parents. (Channa,et al 2018). Opinions of parents are often neglected and not counted in policy making. Every parent dreams to make their child more comprehensive and high-quality education (Bughio et al ,2016) conducted their study under titled' English medium or no English medium: parental perspectives from Pakistan. They conducted their study to know perceptions of parents regarding English as MOI in Sindh. They carried out 11 semi-structured interviews from parents residing in Hyderabad. They concluded that Pakistan has failed to give one school system and parents understand English as a vehicle for good future despite of agreeing on difficulties faced by children in studying English.

Another study was conducted by Channa, Pathan \& Shah in 2018 regarding medium of instruction from parental perspective in Sindh. The outcome of their study showed that parents have myths that if their children were educated in their first language, they would not be able to learn English effectively later. They stated that these myths have been normalized and internalized by improper language policies and excluding parents from policy making process.

A different study was conducted by David \& Manan in 2018 about English medium policy in private schools in Pakistan. They carried out their study in 11 low fees private schools in Quetta to know the perceptions of stakeholders about English and native language. They draw the results that showed English language was proudly preferred at the expense of mother tongue and their ethnic identity. Their right of self-expression was silenced by imposing an alien language in pragmatic ways.

A study was conducted by Ede Iyamu and Sam Ogiebaen in 2007 about the perceptions of teachers and parents regarding mother tongue medium of instructions policy in Nigerian primary schools. They conducted their study by taking two questionnaires from 1000 primary school teachers and 1500 parents of primary school children. Results showed that both teachers and parents were supportive of mother tongue education but parents would not subscribe their children to mother tongue education because of English as a means of wider communication and lack of suitable teaching material in mother tongue.

Parents' attitude towards their child's mother tongue affects their education success. Their involvement, seriousness, and encouragement can influence them to have positive attitudes towards learning their mother tongue. They can increase their children's self-confidence, esteem and pride about who they are what are their roots and help them practice their culture. They can provide resources to support their involvement in learning their mother tongue. In fact, the positive attitude that children hold for learning their mother tongue results from the power of the relationship between them and their parents, and to what extent they are proud of their identity and culture (Hanani, 2009).Generally, different stakeholders think that when kids begin with early-English instruction in school, it will quickly result in better learning of the language as well as course contents; thus, they take for granted that by the time children matriculate from schools, they will have gained greater exposure, command and 
proficiency in the English words (Manan, 2015). Therefore, English is a dream goal of every parent in the Pakistan. This hegemonic behavior of English in Pakistani context has sidelined mother tongue education right and children are stuck in dichotomies of two language and nether getting mastery in two languages in their very young age. This is affecting them psychologically and academically.

\section{Research design:}

This is an exploratory qualitative study. Qualitative research is chosen because it helps to know perceptions of Sindhi parents towards additive and subtractive bilingualism and what outcome one language policy has over their children. Semi-structured interviews have been used as research instruments for this study. A researcher has observed parents in her own home and in her surroundings. Interviews have been taken from parents whose children are studying at primary level. 16 participants have been selected. Out of which 6 are mother and 10 are fathers. Some couples agreed to interview together and others were not comfortable. Therefore, researcher intended to take interview together of married couples but it was not mostly possible. Interviews were taken separately but only few couples agreed to interview together. The data was collected from four districts of Sindh; QambarShahdadkot, Hyderabad, and Dadu. Number of pariticpants from Hyderabad district was five (M=2, $\mathrm{F}=3)$. from Dadu 4 participants were selected $(\mathrm{M}=3 \& \mathrm{~F}=1)$ and from Qamabar and Shehdadokot 4 participants were selected $(\mathrm{m}=2$ \& $\mathrm{f}=2)$. From Jamshoro three participants were selected. Maximum variation sampling was chosen as sampling method for this research article. Data is analyzed using Braun's and Clark's (2006) model of thematic analysis has been used in this study to extract results. While analyzing the data, the researcher had thoroughly examined the problems faced by the children of Sindhi parents in subtractive bilingual education and what they perceive about additive and subtractive bilingual education.

\section{Findings and Results}

By using Braun \& Clarke's model (2006) model 4 major themes have been made which had been aligned with research objectives of the study. These themes are thoroughly discussed below.

Theme 1: Perceptions of parents towards subtractive bilingualism

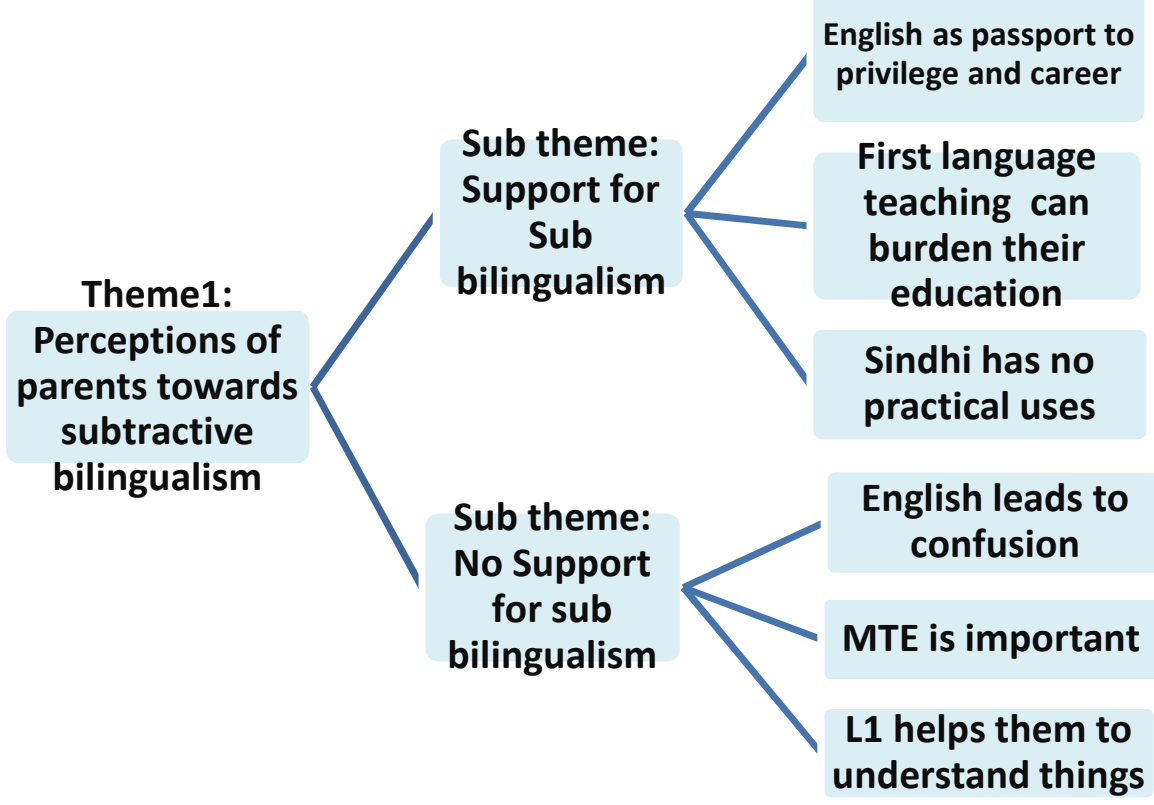

Fig 01

1- Perceptions of Parents towards subtractive bilingualism

a) Support for subtractive bilingualism

- Out of 16 participants, 6 participants explicitly supported Subtractive bilingualism.

- English as a passport for privilege

- All participants in the study undeniably agreed on the role of English as an international and educational language. Among 6 of them supported Subtractive Bilingualism for their children.

- $\quad$ One of the participant stated, "No, I don't support bilingualism because I want if it is Sindhi it must solely be Sindhi. When we were taught we were taught only in Sindhi and that was good. When our children are educated, they must be educated in English because the world is progressing and English is most important to go with the world. Otherwise we will be left behind".

- b) First language can over burden children 
- Participant \# 3 said, "No I don't support bilingualism. we have Sindhi syllabus in early classes but later classes they had to confront English. This duality of languages could lead a child to confusion. It only wastes their energy and leads them to confusion".

- c) Sindhi has no practical use

- Participant statement, ". But when they don't have to do anything in Sindhi so why to burden children to learn Sindhi because it has nothing to do with their future and for our survival English is a must. Therefore, I pressurize them less for Sindhi and more for English".

- 2) Denial for Subtract bilingualism

- 10 participants of the study denied subtractive bilingualism.

- a) English leads to confusion and cramming

- Statement of the participant" When a single language is imposed it would be totally unfair and it will increase their burden leading a child to confusion".

- b) Mother Tongue Education is important

- Participant statement," If children do not get mother tongue education in primary level then they may cut off from their history, culture and traditions, proverbs, folk stories and neither will they take any interest in those things. Take an example of names of week. They would ask us what is aachr (Sunday)?

- c) L1 helps them to understand things

Participant statement," A child learns everything $n$ their language informally and they know how these words combine to form sentences and how to make a concept of something. Being a parent we instruct them in Sindhi to make them things clear and then they can internalize those things to make concepts more complex

\section{Theme 02: Perception of parents towards Additive Bilingualism}

- Out of 16 participants, 10 of them supported additive bilingualism and were not satisfied with English as sole MOI in schools.

- Additive bilingualism as a way to help children more involved in active educational space and maintaining identities.

- One of the participant state," if we see in current scenario, bilingualism only way to protect our language to some extent. Same emphasis should be given on Sindhi as it is on English which cannot be possible in current situation. For a safer side, if a child cannot understand anything in English, then that thing must be taught in their mother tongue. It is only way to keep a child in their own comfort zone and it is also a way to enhance their catching power that they can understand new things and concepts easily and comfortably.

Sub theme 03: Perceptions of parents towards English Language Teaching

a) Sub theme1: No English proficiency

Sample response, " They don 't understand things in English, because there is a

Weird situation for a child because first of all a child has to understand a thing they have to know the meaning".

b) Poor English comprehension

Participant response, "they are not fluent in English. When it comes to reading, they lack reading fluency as well. Their competency is so far good when it comes to examination and then good grades but we are not so far satisfied with their competency. A child has to depend on rote memorization and cramming due to English".

c) Sub theme 3: Lack of quality teachers

Participant response,, "No. English is not taught well in schools especially in Hyderabad. It is not taught at that high level as is in Karachi" 


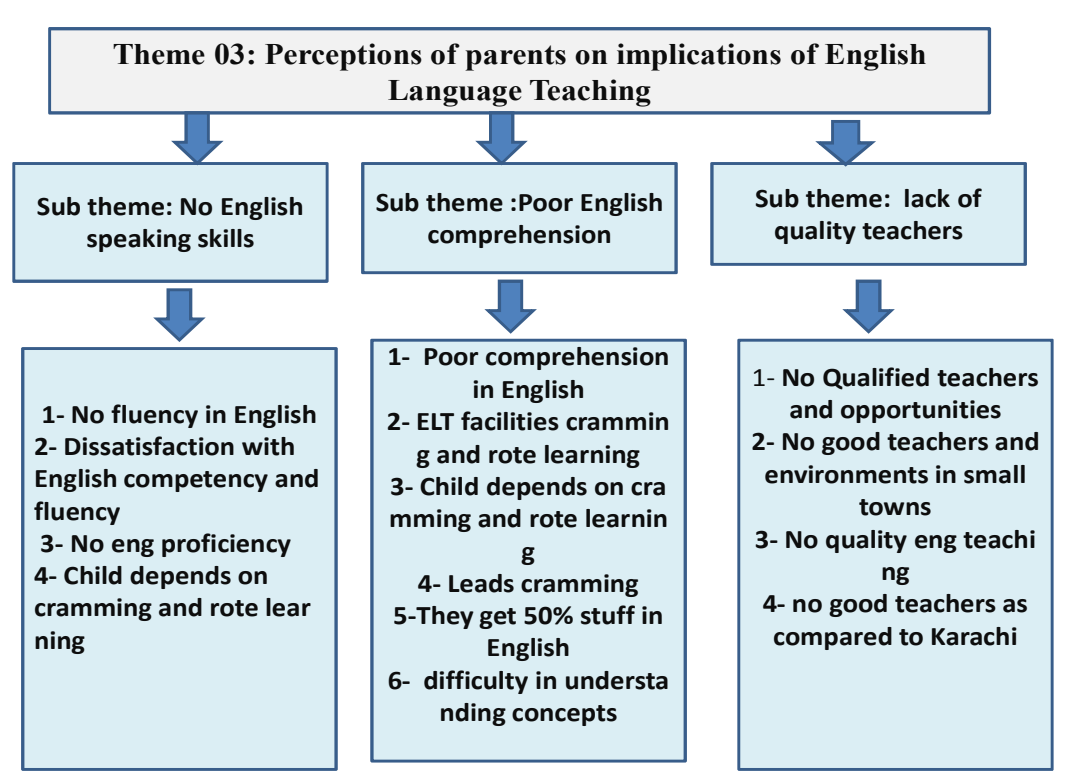

Fig 02

Theme 04: Perceptions of parents towards L1 teaching

- No Sindhi language teaching culture in Hyderabad and big cities

- No Sindhi writing and reading skills.

- Neglect of Sindhi language teaching in private schools

- Children's cultural and linguistic experience in the home is the foundation of their future learning and we must build on that foundation rather than undermine it; every child has the right to have their talents recognized and promoted within the school in their own language (Cummins, 2001).

- $\quad$ Participant response," they can speak but cannot write and read in Sindhi. You can say they only 30\% about reading and writing",

\section{Discussion:}

This study explores the perceptions of Sindhi parents towards medium of instruction policy in educational domain and what language would they like to prefer for their children's academia. However the results were more in favor of additive bilingualism and parents strongly supported mother tongue education and six participants supported subtractive bilingualism. MOI has been politically handled and no serious concern have been given to this much needed issue in this country and what beliefs parents hold about all this scenario is important. Parents are most important stakeholders and their opinion matters most. There has been almost 9 language policies offered in entire history of Pakistan but no language policy have given enough space to mother tongue education. After 90's proliferation in private school, further boosted the use of dominant state languages in educational sites. Private education is most important asset of any nation. How to educate young minds is a core responsibility of any state.

This study explored that every parents in Sindh, Pakistan wanted English for their children but on other hand were not satisfied with English in the schools. Parents explicitly declared that their children have poor proficiency in English and they had only moderate reading and writing skills. They cannot make sense of what they are reading. This study also explored that parents wanted Sindhi language at least as a subject but private schools even do not accept Sindhi as a compulsory subject in their institutions. They take Sindhi or any other language of their no concern and this is affecting children. This unconsciously internalizes children that your language and identity are not being welcomed in educational or other societal spheres (Cummin, 2000, 2009). Every participant was agreed that English is an international language and it is necessary for global communication. They added that English is a language of science and technology and to progress children had to learn it. Few participants were of the opinion that they wish that Sindhi had ample science material that they didn't need English for this but sadly Sindhi desperately lacks material in science.

Majority of participants in the study declared subtractive bilingualism as their mere requirement but they do not take English or any other dominant language as a teaching language for their child's academia. They expressed that English creates troubles for children and they had to waste lot of their energy in first understanding words, sentences and paragraphs and then they little bit get it. Subtractive bilingualism is a serious concern not only for Sindhi overall Pakistan. Language policies which support and implement mother tongue education are highly needed at this crucial and historical time. Otherwise it not only damages children cognitively but have bigger impacts on society. People and identities should be negotiated rather than denied. Language shift and loss are real 
and they are taking place. If language in education will not be served it will result in loss and ultimately death. The hegemony of English and Urdu (Rahman 2005) have sidelined mother tongue education and progressive parents show their concern over this issue but rest of masses have accepted this hegemonic and coercive behavior of dominant languages in the country.

All participants showed their sentimental affiliation with Sindhi and were sad about the reality that their language is not being effectively taught and transmitted to young generation. Maintaining language without educational support is itself a big challenge and in this hustle bustle daily routines parents are unable to pay attention to teaching their children their mother tongue. If not encountered in present day, we would have to face big loss in upcoming future. This study also shows that despite of desperate need to educate children in mother tongue, parents are not seriously taking any action against management and making them strict to teach sindhi. All the parents were agreed that Sindhi teaching starts after $3^{\text {rd }}$ or $4^{\text {th }}$ classes and children do not take much interest in Sindhi either because it is taught in very boring manner. Neither provincial government of Sindh nor parents are taking actions for Sindhi language teaching.

\section{PRACTICAL IMPLICATIONS}

Parents are the bearers of the outcome of children. This study wants to draw attention of policy makers to make aware parents about new theories in the field of education and later take their perspective in policy making. This study also emphasizes the importance of mother tongue education at least at primary schooling which would not only benefits children but whole society whose importance has been raised by UN and many countries are favoring additive bilingualism

\section{Conclusion and Suggestions}

This study explored perception of parents about subtractive and additive bilingualism and showed that parents showed dissatisfaction with English language teaching and rather than helping it creates trouble for children at their very young and tender years of their lives. Therefore mother tongue education should be incorporated along with English language teaching to keep children at their comfort zone and help them to understand concepts , world and their true being.

\section{References}

Al-Qahtani, Z., \& Al Zumor, A. W. (2016). Saudi parents' attitudes towards using English as a medium of instruction in private primary schools. International Journal of Applied Linguistics and English Literature, 5(1), 18-32.

ASER, 2014: Annual status of education report, Islamabad Pakistan, ASER Pakistan.

Creswell, J.W. (2002). Educational Research: Planning, conducting, and evaluating qualitative and quantitative research. New Jersey: Pearson Education: Upper Saddle River.

Fillmore, W. (1991). When learning a second language means losing the first. Early Childhood Research Quarterly, $6(3), 323-346$

Hanani, F. (2009). Impact of English on Young Arabs' Use of Arabic in the UAE (Doctoral dissertation).

Utaravichien, A. (2014). Maintaining the Mother Language: Perceptions of Thai Parents in the United States (Doctoral dissertation, Sam Houston State University).

Utaravichien, A. (2014). Maintaining the Mother Language: Perceptions of Thai Parents in the United States (Doctoral dissertation, Sam Houston State University).

Singh, M. V., Gupta, M. N., \& Kulkarni, M. H. (2019). IMPORTANCE OF MOTHER TONGUE IN PRIMARY EDUCATION. IJRAR-International Journal of Research and Analytical Reviews (IJRAR), 6(1), 19-24.

Siddiqui, F. K. (2018). Problems of educational management in the private sector relating to the elementary education in Sindh. Grassroots, 47(1).

Manan, S. A., Dumanig, F. P., \& David, M. K. (2017). The English-medium fever in Pakistan: Analyzing policy, perceptions and practices through additive bi/multilingual education lens. International Journal of Bilingual Education and Bilingualism, 20(6), 736-752.

Iyamu, E. O., \&Ogiegbaen, S. E. A. (2007). Parents and teachers' perceptions of mother-tongue medium of instruction policy in Nigerian primary schools. Language, culture and curriculum, 20(2), 97-108.

May, S. (2017). Bilingual education: What the research tells us. Bilingual and Multilingual Education. Encyclopedia of Language and Education. 3rd ed. Cham, Switzerland: Springer, 81-100.

David, M. K., Ali, M., \& Baloch, G. M. (2017). Language shift or maintenance: The case of the Sindhi language in Pakistan. Language Problems and Language Planning, 41(1), 26-45.

Panhwar, F., Lone, S. T., \& Muhammad, A. F. (2019). The Looming Extinction of Sindhi Language in the Urban Context and Role of A Sindhi Mother. The Women-Annual Research Journal of Gender Studies, 11(11).

Skutnabb-Kangas, T., \& McCarty, T. L. (2008). Key concepts in bilingual education: Ideological, historical, epistemological, and empirical foundations. Encyclopedia of language and education, 5(17), 1466-1482. 
Lambert, W. E., (1981). Bilingualism: Its nature and significance. In W.E. Lambert, C.E. Snow, B.A. Goldfield, A.U. Chamot, \& S.R. Cahir (Eds.), Bilingual educational series 10; Faces and facets of bilingualism. Washington, DC: Center for Applied Linguistics.

Sandelowski, M. (1995). Focus on quantitative methods: Sample sizes, in qualitative research. Research in Nursing and Health, 18, 179-183.

Cummins, J. (1991). Interdependence of first- and second-language proficiency in bilingual children. In E. Bialystok (Eds), Language processing in bilingual children (pp. 70-89). New York, NY: Cambridge University Press. 